\title{
PERCEPÇÃO AMBIENTAL DA POPULAÇÃO SOBRE A ARBORIZAÇÃO URBANA DO BAIRRO CENTRO NO MUNICÍPIO DE AREALVA, SÃO PAULO
}

\author{
ENVIRONMENTAL PERCEPTION OF THE POPULATION ABOUT THE URBAN \\ FORESTS AT DOWNTOWN IN THE MUNICIPALITY OF AREALVA, SÃO PAULO
}

\author{
Carolina Garcia de Almeida', Bianca Cristina Costa Gêa², Marcos Vinícius Bohrer Monteiro Siqueira ${ }^{3}$
}

\section{RESUMO}

As árvores no meio urbano geram melhor qualidade de vida, valorizando a beleza estética das ruas, conforto térmico e preservação da biodiversidade. Entender como a população visualiza seu ambiente pode auxiliar o município na gestão da arborização. O trabalho objetivou analisar a percepção ambiental dos moradores em relação à arborização urbana do município de Arealva-SP. A coleta de dados foi baseada em um grupo amostral, composto por 115 moradores escolhidos aleatoriamente, na área central da cidade, através de um formulário. Entre os dados obtidos destaca-se que $49,57 \%$ dos participantes classificaram sua rua como pouco arborizada, $50,43 \%$ elegeram a sombra como maior vantagem, $37,4 \%$ elegeram problemas com a rede elétrica como maior desvantagem, 60,8\% responsabilizaram a arborização urbana à prefeitura e à população. Os dados mostraram o conhecimento limitado dos moradores sobre o tema, uma vez que apontaram como principais vantagens sombra $(50,43 \%)$ e redução de calor $(23,48 \%)$. Uma pequena parcela de $12,17 \%$ dos indivíduos amostrados conseguiram relatar as diferentes vantagens que as árvores proporcionam, como beleza estética e preservação da biodiversidade. A semelhança de dados obtidos em outras cidades da região, a ação do poder público local poderia mudar a qualidade da arborização e consecutivamente a percepção ambiental dos moradores.

Palavras-chave: Áreas verdes urbanas; Educação ambiental; Qualidade de vida; Planejamento urbano.

\begin{abstract}
Trees in the urban environment generate better quality of life, valuing the aesthetic beauty of the streets, providing thermal comfort and preserving the biodiversity. Understanding how the population views their environment can assist the municipality in the urban forest management. The study aimed to analyze the environmental perception of the residents in relation to the urban forest of Arealva, SP. Data collection was based on a sample group of 115 randomly selected residents in the central area of the city using a form. Through data obtained, it was verified that $49.57 \%$ of the participants classified their street as poorly wooded, $50.43 \%$ chose the shade as the highest advantage, $37.4 \%$ chose problems with the electric grid as the highest disadvantage, $60.8 \%$ consider responsible for the urban forest the city's government and the population. The data showed the residents' limited knowledge on the subject, as they pointed out as main advantages shade $(50.43 \%)$ and heat reduction $(23.48 \%)$. A small portion of $12.17 \%$ of the individuals sampled were able to report the different advantages that trees provide, such as aesthetic beauty and biodiversity preservation. In resemblance to data obtained in other cities in the region, the action of local public authorities could change the quality of urban afforestation, and consequently the environmental perception of residents.
\end{abstract}

Keywords: Urban green areas; Environmental education; Life quality; Urban planning.

Recebido em 12.05.2019 e aceito em 09.09.2019

1.Graduada em Engenharia Ambiental e Sanitária. Universidade do Sagrado Coração. Bauru/SP. Email: carolgarcia.usc@hotmail.com

2 Graduanda em Engenharia Agronômica. Universidade do Sagrado Coração. Bauru/SP. Email: biaccgea@gmail.com

3 Técnico de Gestão Ambiental. Dr. Faculdade de Ensino Superior e Formação Integral. Garça/SP. Email: mvbsiqueira@gmail.com 


\section{INTRODUÇÃO}

Nas últimas décadas, com o avanço da industrialização e a busca por melhores condições de vida, houve uma intensa migração da população rural para os centros urbanos, os quais, por falta de planejamento adequado, cresceram desordenadamente, alterando as características climáticas do meio, afetando a qualidade de vida de seus habitantes e distanciando os mesmos de uma relação harmoniosa com a natureza (SANTOS et al., 2018). Essa urbanização favoreceu, assim, o crescimento desordenado, rápido e sem planejamento das cidades em grande parte do território nacional (ROPPA et al., 2007).

As árvores são consideradas uma ferramenta de grande importância para aumentar a qualidade de vida da população, visto que, além de valorizar a beleza estética das ruas, geram conforto térmico para os moradores e auxiliam nas questões sociais, visto que, em recintos urbanos arborizados, as copas das árvores reduzem o fator de céu visível e, consequentemente, geram o resfriamento passivo do recinto (ROLON; SIQUEIRA, 2018).

A arborização urbana é um fator que vem sendo levado cada vez mais em conta no que diz respeito a pesquisas sobre a qualidade de vida nas cidades (OLIVEIRA; TAVARES, 2012). Quando não há um planejamento adequado dessa arborização, as cidades têm que lidar com diversos problemas, como danos na fiação elétrica e telefônica, sujeiras nas sarjetas, quebra de calçadas, e acidentes com quedas de galhos. Para contornar ou minimizar esses problemas, é necessário o conhecimento sobre quais são as espécies arbóreas adequadas ao plantio nas vias públicas e seu contínuo manejo (CABRAL, 2013).

A manutenção correta das áreas arborizadas nas vias urbanas se torna difícil (em parte) devido à falta de participação da comunidade, e à ausência de sensibilidade ambiental quanto a real importância dos espaços verdes. Embora já existam diversos estudos sobre a percepção ambiental relacionada à arborização urbana (GROSS et al., 2012; LOURENÇO, 2017; SUFIA; SOUZA; SIQUEIRA, 2019), as análises qualiquantitativas, podem ser distintas nas diferentes localidades. Deste modo, tais pesquisas são necessárias para se conhecer os anseios e necessidades da população, visto ser esta a que sente diretamente o impacto da qualidade ambiental a partir da manutenção da biodiversidade dos espaços urbanos de seu município. Ao perceber o ambiente que os cerca, a sensibilização para a preservação tornase mais fácil, sendo possível se determinar soluções duradouras para minimizar os problemas ambientais (RODRIGUES et al., 2010; SUFIA; SOUZA; SIQUEIRA, 2019).

A análise da população sobre a gestão, planejamento e a manutenção da arborização urbana pode ser incentivada pela educação ambiental. A partir dos estudos de percepção ambiental é possível reunir dados e informações relevantes para a elaboração de 
projetos e políticas públicas de sustentabilidade nas cidades, sensibilizando a população sobre a importância da manutenção das árvores nas vias públicas, e sobre o papel do cidadão na manutenção de um ambiente equilibrado (HO et al., 2015).

Apesar da temática estar cada vez mais presente nas discussões e reflexões da nossa sociedade, o histórico de publicações científicas acerca do assunto proposto ainda é escasso (RODRIGUES et al., 2010). Dessa forma, o presente estudo ganha mais relevância, uma vez que será possível gerar um diagnóstico atual, podendo servir como incentivo para futuros trabalhos e pesquisas similares em outros municípios do estado. Assim, o objetivo desse trabalho foi analisar a percepção ambiental dos moradores em relação à arborização urbana no município de Arealva, SP.

\section{MATERIAL E MÉTODOS}

A pesquisa foi realizada na cidade de Arealva-SP. Esta situa-se na latitude $22^{\circ} 01^{\prime} 43^{\prime \prime}$ sul e longitude 4854'40" oeste, a uma altitude de 445 metros. Possui uma área de 506,465 $\mathrm{km}^{2}$ e está a $370 \mathrm{Km}$ da Capital, à margem esquerda do rio Tietê (IBGE, 2019). A pesquisa aqui apresentada faz parte de um projeto de maior escala que envolve várias cidades do Centro Oeste de São Paulo.

Segundo o Instituto Brasileiro de Geografia e Estatística (2017), o município possui uma população estimada de 8.505 pessoas. Apresenta $90,2 \%$ de domicílios com esgotamento sanitário adequado, 95,7\% de domicílios urbanos em vias públicas com arborização e 13,8\% de domicílios urbanos em vias públicas com urbanização adequada (presença de bueiro, calçada, pavimentação e meio-fio).

A área escolhida para a aplicação dos formulários foi a região onde encontra-se a Praça Central Igreja Matriz, visto ser o local mais movimentado e com maior número de moradores (aproximadamente 1.693 habitantes). Foram percorridas todas as doze ruas ao redor da praça, três quarteirões acima, abaixo e lateralmente à praça (Figura 1). 


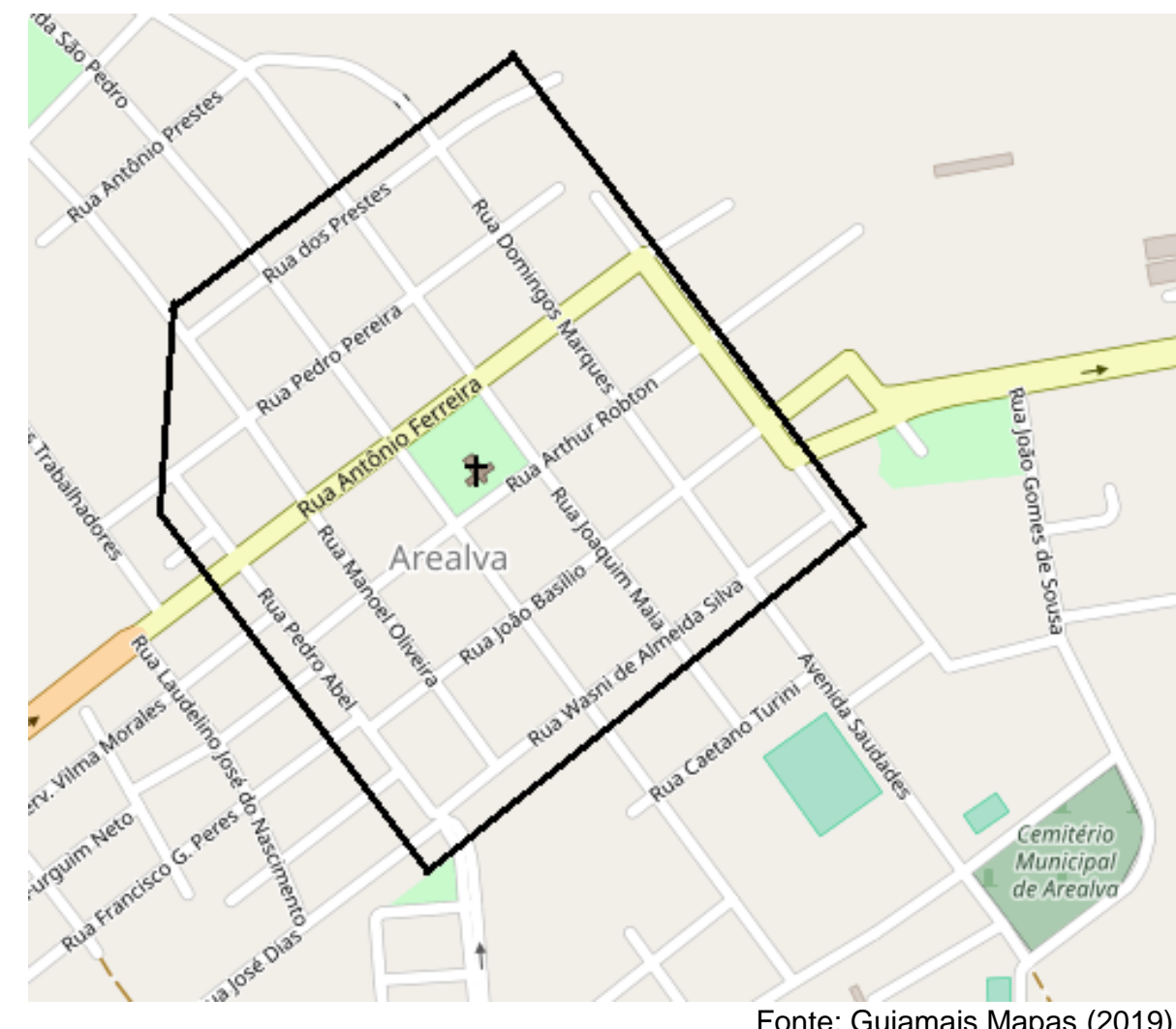

Figura 1. Local de aplicação dos formulários - Praça Central de Arealva - SP Figure 1. Place of forms application - Arealva Central Plaza - SP

A coleta de dados foi realizada a partir de um formulário previamente elaborado contendo questões objetivas e questões do tipo aberta (Figura 2). O critério adotado para a aplicação do formulário foi a idade mínima de 18 anos para os participantes, em que mais de um residente do imóvel poderia responder ao questionário. Baseado no estudo de Santos et al. (2018), consultaram-se residências de forma não padronizada em ambos os lados da rua, seguindo-se um delineamento experimental não aleatório. O período de aplicação dos questionários foi entre junho e julho de 2018, em que foram entrevistados, ao todo, 115 moradores via amostragem, o que correspondeu a aproximadamente $6,8 \%$ dos moradores do Bairro Centro. 


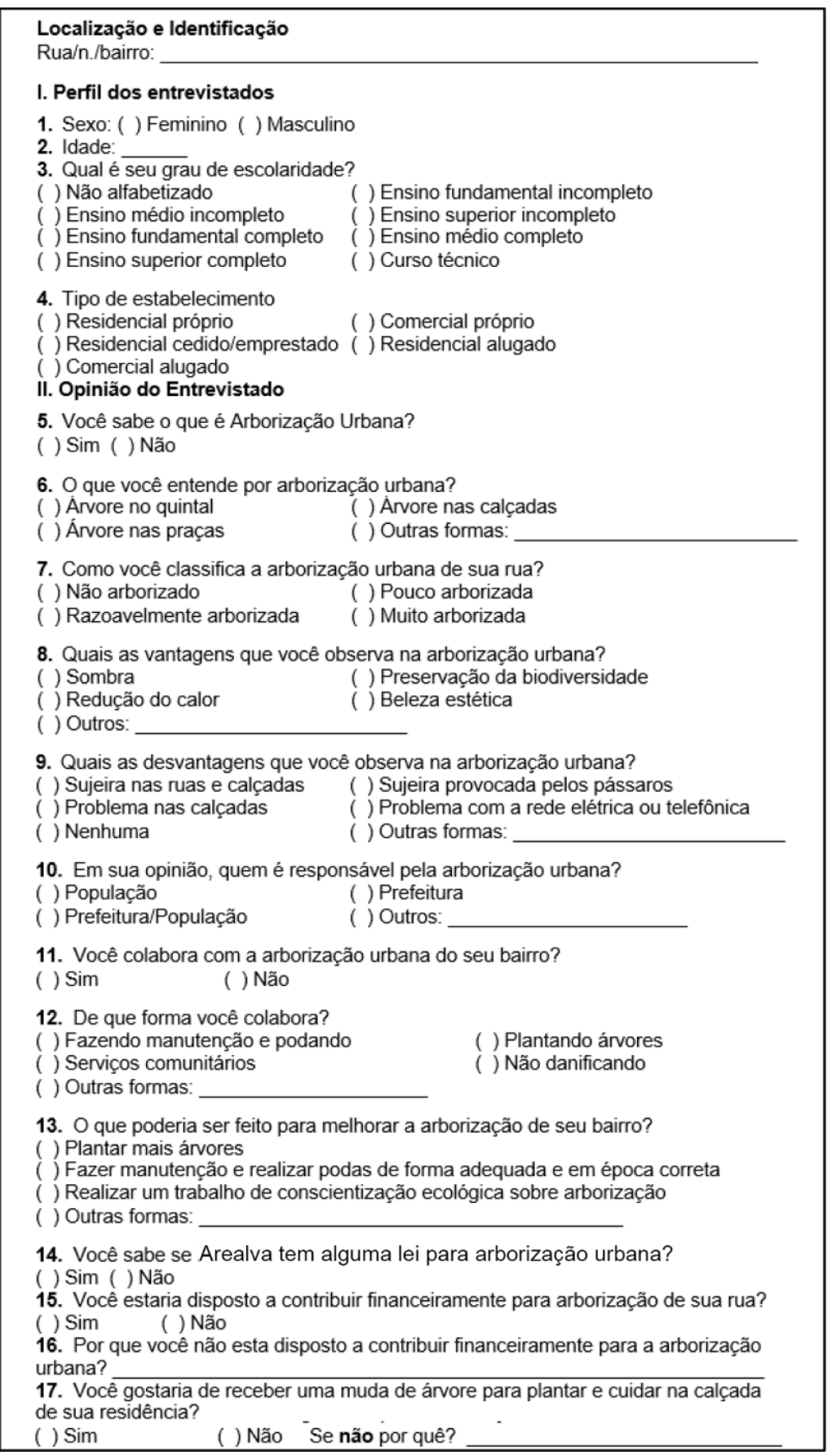

Figura 2. Formulário de avaliação da percepção ambiental na cidade de Arealva - SP

Figure 2. Evaluation form of environmental awareness regarding in the city of Arealva - SP

Durante a aplicação dos formulários, as alternativas não eram lidas aos entrevistados para que não fossem influenciados e, assim, pudesse ser obtida a real opinião de cada morador. Depois de efetuadas as entrevistas formais, os dados obtidos foram compilados e analisados a fim de observar a percepção da população em relação à arborização urbana. Foram utilizadas planilhas informatizadas contidas no software Microsoft Excel 2016 tendo sido obtidas as frequências absolutas para as diferentes questões. 


\section{RESULTADOS E DISCUSSÃO}

\section{Perfil socioeconômico dos entrevistados}

Ao todo, foram realizadas 115 entrevistas (a partir de uma população estimada em 1.691 habitantes), o que representa $6,8 \%$ dos moradores do bairro, onde $59 \%$ eram mulheres e $41 \%$ homens. A idade dos entrevistados variou entre 19 e 77 anos. A análise do perfil dos entrevistados demonstrou que a maioria dos moradores possui idade entre 45 e 65 anos, representando $36,52 \%$ do total de participantes. Em relação ao tipo de residência, 75\% afirmaram ser própria e $25 \%$ alugadas (Tabela 1). Nenhum dos entrevistados foi abordado em pontos comerciais. Dados semelhantes foram obtidos por Sufia, Souza e Siqueira (2019) na qual aproximadamente $76 \%$ dos moradores de Bauru - SP, possuíam residência própria e $15 \%$ alugada. Estas informações, segundo os autores, tornam-se pertinentes uma vez que pode existir uma percepção ambiental mais ampla sobre a arborização do bairro quando as residências são próprias, tendo em vista que o morador que adquire imóvel em determinada localidade, o faz com ânimo definitivo e, portanto, zela pelo seu bem-estar, inteirando-se das comodidades locais e de tudo que o cerca (SUFIA; SOUZA; SIQUEIRA, 2019).

Tabela 1. Perfil socioeconômico dos entrevistados do bairro centro do município de Arealva - SP

Table 1. Socioeconomic profile of the interviewees from the downtown district of the city of Arealva $\mathrm{SP}$

\begin{tabular}{|c|c|}
\hline Variáveis & Número de entrevistados \\
\hline Gênero & \\
\hline Feminino & 68 \\
\hline Masculino & 47 \\
\hline \multicolumn{2}{|l|}{ Faixa etária } \\
\hline Entre 18 e 30 & 25 \\
\hline Entre 31 e 45 & 36 \\
\hline Entre 46 e 65 & 42 \\
\hline Mais que 65 & 12 \\
\hline \multicolumn{2}{|l|}{ Estabelecimento } \\
\hline Residência própria & 86 \\
\hline Residência alugada & 29 \\
\hline \multicolumn{2}{|l|}{ Escolaridade } \\
\hline$N A^{*}$ & 5 \\
\hline $\mathrm{EFI}^{*}$ & 13 \\
\hline $\mathrm{EFC}^{*}$ & 18 \\
\hline $\mathrm{EMI}^{*}$ & 19 \\
\hline EMC* & 23 \\
\hline $\mathrm{ESI}^{*}$ & 6 \\
\hline ESC* $^{*}$ & 31 \\
\hline
\end{tabular}


Ao analisar o grau econômico e de escolaridade dos entrevistados, observou-se que há uma ampla distribuição de classes sociais e níveis de ensino. Portanto, todas as variáveis utilizadas no formulário mostraram que pessoas com diferentes perfis socioeconômicos participaram da pesquisa. Estudar o perfil socioeconômico com o auxílio da pesquisa, é utilizado como variável explicativa ou de controle para análise de diversos fenômenos sociais (ALVES; SOARES, 2009), sendo amplamente caracterizado em trabalhos de percepção ambiental. Segundo Monteiro et al. (2013), elaborar um perfil socioeconômico dos entrevistados em estudos de percepção ambiental é importante não apenas para se conhecer os moradores do local, mas também para facilitar as ações de educação ambiental sobre assuntos específicos.

\section{Quantidade arbórea, vantagens e desvantagens da arborização urbana}

Quando questionados sobre "o que é arborização urbana?" (o questionário permitia apenas a resposta "sim" ou "não"), sendo que 79,13\% dos entrevistados responderam que sabiam do que se tratava, ou tinham uma certa ideia a esse respeito; 20,87\% responderam que não sabiam sobre o assunto. A definição mais mencionada pelos que responderam que sabiam o conceito de arborização urbana, limitava-se às árvores plantadas nas calçadas, sem considerar as praças e árvores nos quintais, representando $80,22 \%$ das opiniões. Sufia, Souza e Siqueira (2019) apresentaram em seus resultados que 38\% dos entrevistados do bairro Parque Santa Edwiges, em Bauru, SP, sabiam ou já tinham ouvido falar sobre o termo, enquanto no bairro Parque Jardim Europa, 59\% disseram possuir conhecimento acerca do assunto. O conceito de Arborização Urbana é mais abrangente e completa que os obtidos pelos moradores da cidade de Arealva, bem como nos demais trabalhos publicados sobre percepção. Milano (1992) conceitua arborização urbana como o "conjunto de terras públicas e privadas com vegetação predominantemente arbórea ou em estado natural que uma cidade apresenta" e neste inclui as árvores de ruas e avenidas, parques públicos e demais áreas verdes. Outras definições semelhantes podem ser obtidas por Jorgensen (1970) e Miller (1997).

Em relação à quantificação arbórea, a maioria dos entrevistados descreveram como pouco arborizada, representando $49,57 \%$ do total de participantes. Os que consideraram muito arborizada representaram 4,35\%, razoavelmente arborizada $28,7 \%$ e não arborizada $18,26 \%$. De forma geral, não houve convergências entre as percepções relatadas pelos participantes e a real situação das áreas estudadas. É possível notar que as pessoas que classificaram sua rua como "muito arborizada" foram aquelas que residiam perto da Praça Central Igreja Matriz. Essa questão tende a ser muito subjetiva, pois o entrevistado pode levar 
em consideração apenas árvores presentes próximas às suas casas, e não na rua como um todo, onde existem quadras que apresentam números mínimos de indivíduos arbóreos, muitas vezes com apenas uma ou duas espécies (RODRIGUES et al., 2010).

Devido a cidade não ter uma distribuição uniforme da arborização, gerou-se respostas diferentes entre os entrevistados, pois a quadra de um morador era mais arborizada do que a do outro, o que se comprovou na desigualdade das percepções. O município como um todo possui uma distribuição irregular de suas árvores, sendo muito arborizada em algumas partes e, em outras, não, fato que foi confirmado pelos moradores durante as entrevistas formais. É possível verificar na quadra à frente da praça central, onde está localizada a Igreja Matriz, que existem apenas duas árvores plantadas, situação semelhante observada a duas quadras abaixo da praça, onde há somente quatro árvores plantadas (Figura 3).
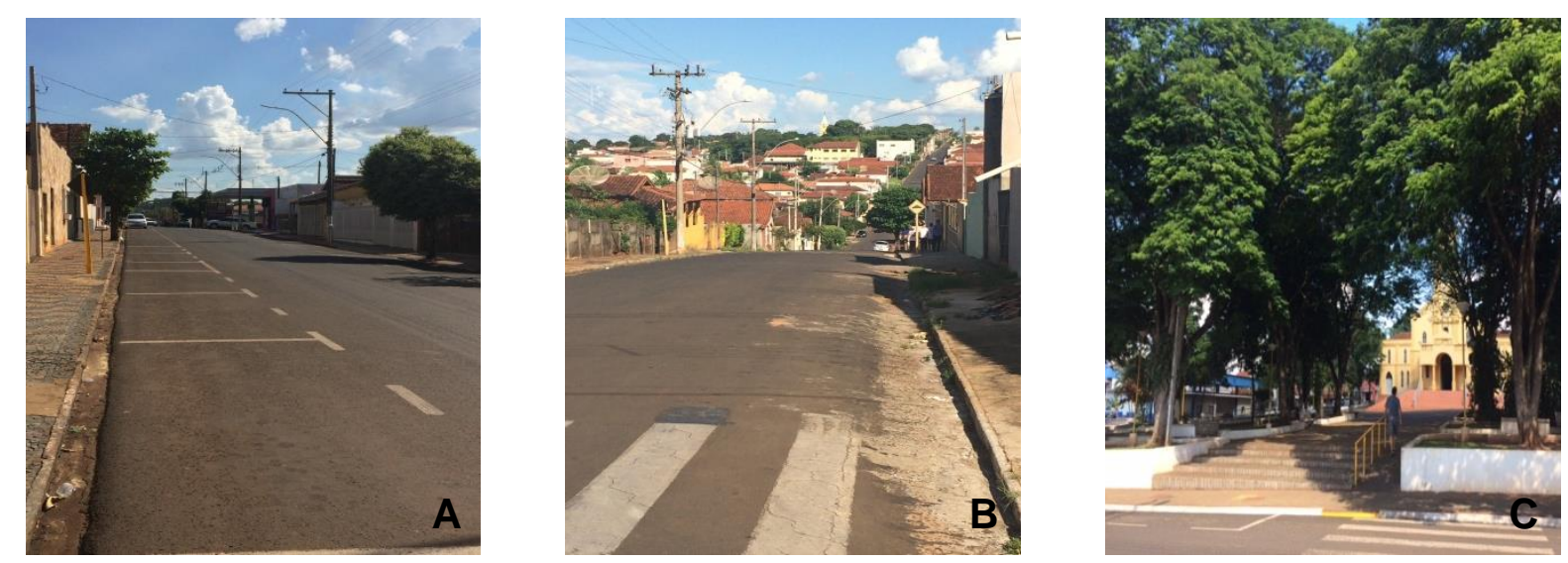

Figura 3. Diferentes números de indivíduos arbóreos/arbustivos nas ruas Antônio Ferreira (A), Eliazar Braga (B) e da praça central Igreja Matriz (C) em Arealva - SP

Figure 3. Different numbers of arboreal / shrub individuals at the streets Antônio Ferreira (A), Eliazar Braga (B) and the central square of the Mother Church (C) in Arealva - SP

Em relação às vantagens da arborização, o que os entrevistados consideraram como maior importância foi a sombra, totalizando $50,43 \%$ das respostas, seguida da redução do calor, com 23,48\%, estética e preservação da biodiversidade, com 20,9\%, e 5,3\% para outras vantagens. Dados obtidos nos trabalhos de Rodrigues et al. (2010) e Lacerda et al. (2010) também apresentaram a sombra e a redução de calor como as principais vantagens e maiores contribuições da arborização. Nos estudos de Ho et al. (2015), a redução do calor também foi considerada importante, porém, os entrevistados não consideraram a sombra como fator importante, apresentando um resultado de apenas $6 \%$ entre as contribuições da arborização urbana. A respeito das desvantagens da arborização, os aspectos mais relatados pelos participantes foram: (1) problemas com rede elétrica $(37,40 \%)$; (2) sujeiras nas ruas e 
calçadas $(35,4 \%)$; problemas nas calçadas $(27,82 \%)$ (Figura 4). Nos estudos efetuados por Rodrigues et al. (2010), Gross et al. (2012), e Souza, Cardoso e Silva (2013), os autores concluíram que os problemas na rede elétrica e nas calçadas compõem a percepção ambiental negativa dos indivíduos amostrados. Oliveira et al. (2017) apontaram que a sujeira nas ruas e calçadas apresentou a maior porcentagem de desvantagens na pesquisa, realizada na cidade de Paragominas (PA). Segundo Gonçalves, Coral e Siqueira (2017), as desvantagens da arborização urbana de lbitinga (SP), citadas pelos entrevistados dessa cidade, indicaram uma grande falta de planejamento adequado, visto que não foram seguidos critérios técnicos para a escolha das espécies.
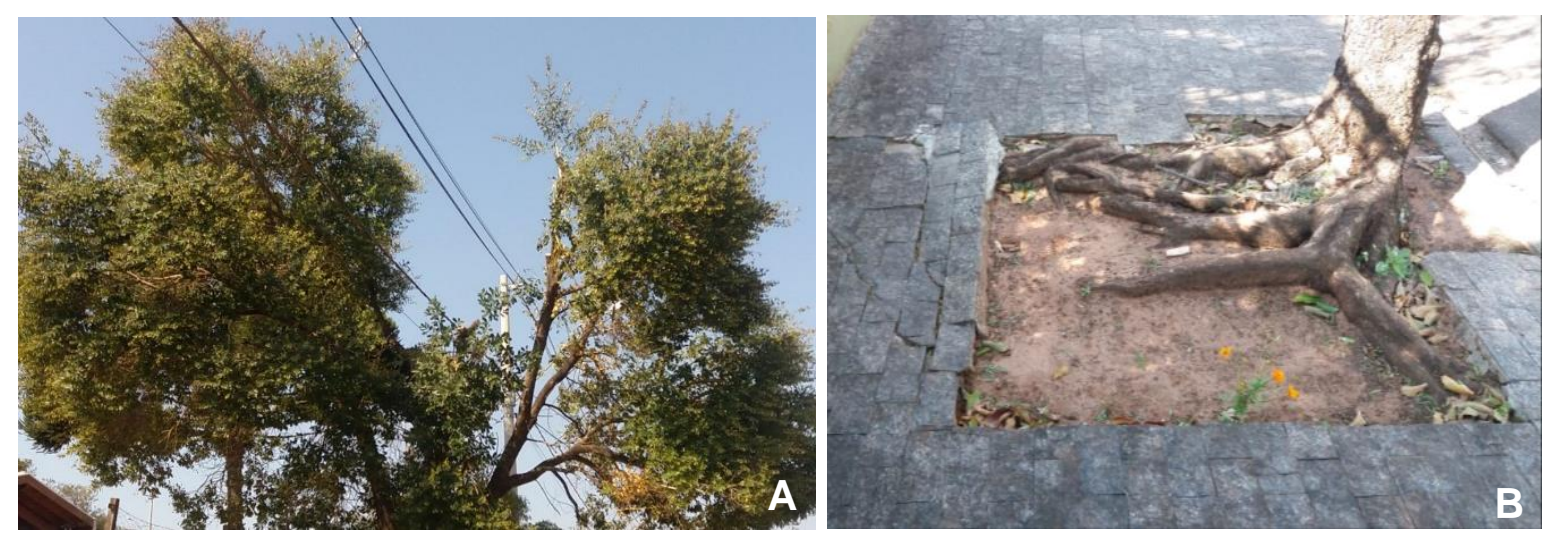

Figura 4. Problemas observados com a rede elétrica e calçadas nas ruas João Basílio (A) Jacinto Ribeiro de Barros (B) em Arealva - SP

Figure 4. Problems observed with the eletric grid and sidewalk in the streets Antônio Ferreira $(A)$, Eliazar Braga (B) in Arealva - SP

Durante as entrevistas foi notório que os entrevistados conseguiram discutir mais sobre as desvantagens do que sobre as vantagens, uma vez que as respostas "sombra e redução de calor" foram quase que unânimes. Em relação ao total de pessoas entrevistadas, foram poucas as que pensaram na conservação da biodiversidade e na beleza estética. Uma das hipóteses para essa diferença, pode ser a falta de conhecimento dos entrevistados sobre os benefícios que a arborização traz para a fauna e flora no cenário urbano. A partir dos relatos podemos apontar que grande parte dos entrevistados não refletem sobre os benefícios trazidos para a cidade como um todo, mas apenas como benefício próprio.

\section{Responsabilidade sobre a manutenção, conservação e implantação da arborização urbana}

Quando questionados sobre a responsabilidade da manutenção da arborização urbana, uma pequena parte dos entrevistados (14\%) responsabilizou somente a população; outra pequena parte $(25,2 \%)$ responsabilizou somente a Prefeitura, e a maior parte dos 
participantes entendem que a responsabilidade deve ser tanto da Prefeitura quanto da própria população (60,8\%). Dados obtidos por Lacerda et al. (2010), na cidade de São José de Piranhas (PB), apontam que $46,4 \%$ do total de entrevistados também responsabilizam a população pela arborização urbana. Ho et al. (2015), em estudo realizado da região central de Mandirituba/PR, mostraram que apenas $19 \%$ de seus entrevistados responsabilizaram a população e $66 \%$ responsabilizaram a população e a Prefeitura, resultado que mais se aproximou do encontrado em Arealva. O artigo 225 da Constituição Federal de 1988 prevê que é de responsabilidade do poder público e da coletividade o dever de defendê-lo e preservá-lo, assim como estabelece no $\S 12^{\circ}$ e $2^{\circ}$ deveres e obrigações do poder público e da coletividade e no $\S$ 3ำ punições à pessoa física ou jurídica que descumprir o que estabelece este artigo (BRASIL, 1988).

Segundo Santos et al. (2018), em estudo realizado na cidade de Tefé (AM), 55\% de seus entrevistados responsabilizaram a própria população pela arborização urbana. Shams, Giacomeli e Sucomine (2009), a partir da análise de trabalhos realizados em diferentes cidades do Brasil acerca dos espaços livres públicos e arborização urbana, sublinham que arborizar uma cidade requer planejamento, e fazê-lo sem critérios pode trazer prejuízos tanto para o poder público quanto à população. Em uma pesquisa ampla realizada por Bobrowski e Biondi (2016), via online, por meio de uma enquete eletrônica, pode-se concluir que somente com a atuação conjunta dos órgãos públicos e da população é possível ter uma arborização adequada.

Uma pequena parcela (22,6\%) dos entrevistados em Arealva afirmou não ter interesse em contribuir financeiramente para o melhoramento da arborização no bairro, mas a grande maioria $(77,4 \%)$ teria intenção de fazê-lo. Nos estudos conduzidos por Frota (2011), apenas $4 \%$ dos entrevistados afirmaram não terem interesse em contribuir com a arborização, enquanto o restante afirmou contribuir de algum modo, mesmo que não financeiramente. As formas de contribuição mais citadas foram não danificando as árvores (55,65\%), realizando podas $(22,61 \%)$ e plantando mais árvores $(21,74 \%)$, porém, a contribuição a partir do serviço comunitário não foi citada por nenhum deles. Araújo, Araújo e Araújo (2010) relataram que em Campina Grande - PB, 35\% dos entrevistados colaboraram plantando árvores, seguido de $26 \%$ que afirmaram contribuir de forma a não danificar a vegetação. Ainda segundo os autores, foi possível de identificar ao longo das entrevistas que os moradores que afirmaram colaborar com a arborização, plantando árvores, na verdade plantaram árvores não recomendadas para calçadas, originando diversos problemas com sujeira e fiação elétrica (ARAÚJO; ARAÚJO; ARAÚJO, 2010). 
Sobre como melhorar a arborização na rua, a questão que mais se destacou foi a "manutenção com podas adequadas" (49,6\%), seguido por "plantar mais árvores" (31,3\%) e "realizar um trabalho de conscientização ecológica" (19,1\%). Esse resultado é compreensível, uma vez que ao transitar pelas ruas do município, é possível notar um considerável número de árvores em que suas podas foram realizadas incorretamente, sendo muitas delas sem chances de reabilitação. Oliveira et al. (2017) destacam que é muito comum no país observar moradores realizando podas incorretas, onde somente pessoas habilitadas e treinadas deveriam executá-la, prevenindo danos ao meio físico e até mesmo possíveis acidentes. Roppa et al. (2007), em estudo realizado em Santa Maria/RS, afirmaram que 47,7\% dos entrevistados citam o plantio de árvores como a principal forma de melhorar a arborização no município, seguido de manutenção e poda adequada, com 46\%. Em Campina Grande/PB, os entrevistados citaram como principais ações de melhorar a arborização urbana da cidade, o plantio de novas árvores (40\%), manutenção e práticas rotineiras de poda (15\%), e cerca de $45 \%$ dos participantes desse estudo, sugeriram um trabalho de conscientização ecológica sobre a arborização (ARAÚJO; ARAÚJO; ARAÚJO, 2010).

\section{CONCLUSÕES}

Ficou evidenciado que, apesar de uma alta parcela dos entrevistados saber o que é arborização urbana, identificou-se pouco conhecimento sobre percepção ambiental entre estes moradores, visto que a grande maioria não conseguiu relatar as inúmeras vantagens que as árvores proporcionam. Não obstante, metade dos entrevistados apontaram que sua rua é pouco arborizada, identificando igualmente, problemas que as poucas árvores urbanas existentes acarretam, evidenciando uma significativa percepção ambiental. Destaca-se que muitos moradores se declararam responsáveis pela arborização urbana juntamente com a prefeitura, e a grande maioria contribui ou pretende contribuir com melhorias, fato muito importante, visto que a participação da comunidade é essencial para a gestão desses bairros. Devido à importância do tema, espera-se que os dados obtidos nessa pesquisa auxiliem os gestores na elaboração de programas de educação ambiental e políticas públicas relacionadas à arborização urbana local. É de fundamental importância que o poder público local realize atividades e campanhas em parcerias com escolas e companhias privadas, a fim de garantir aos habitantes todos os benefícios proporcionados pela presença de árvores nas vias urbanas da cidade de Arealva. 


\section{AGRADECIMENTOS}

Gostaríamos de agradecer as correções e sugestões dos revisores bem como à Mirian Cury pelas melhorias no manuscrito.

\section{REFERÊNCIAS}

ALVES, M. T. G.; SOARES, J. F. Medidas de nível socioeconômico em pesquisas sociais: uma aplicação aos dados de uma pesquisa educacional. Opinião Pública, Campinas, v. 15, n. 1, p. 1-30, 2009.

ARAúJO, J. D. L. O.; ARAúJO, A. C.; ARAúJO, A. C. Percepção ambiental dos residentes do bairro Presidente Médici em Campina Grande, PB, no tocante à arborização local.

Revista Brasileira de Arborização Urbana, Piracicaba, v. 5, n. 2, p. 67-81, 2010.

BOBROWSKI, R.; BIONDI, D. Percepção e preferência popular por atributos estéticos e ecológicos na composição da arborização de ruas. Revista Floresta, Curitiba, v.46, n. 1, p.123-133, 2016.

BRASIL. Constituição da República Federativa do Brasil de 1988. Diário Oficial da União. 5 out. 1988.

CABRAL, P. I. D. Arborização urbana: problemas e benefícios. Revista Especialize On-line IPOG, Goiânia, v. 1, n. 006, s/p, 2013.

GONÇALVES, W. B.; CORAL, D. J.; SIQUEIRA, M. V. B. M. Caracterização da arborização urbana no bairro centro do município de lbitinga/SP. Revista da Sociedade Brasileira de Arborização Urbana, Piracicaba, v. 12, n. 3, p. 66-79, 2017.

GROSS, A.; DORS, P.; CAMPOS, K. A. de; SILVA, A. C. da; HIGUCHI, P. Percepção dos moradores e avaliação da arborização em bairros periféricos na cidade de Lages, SC.

Revista da Sociedade Brasileira de Arborização Urbana, Piracicaba, v. 7, n. 2, p. 24-36, 2012.

HO, T. L.; KOVALSYKI, B.; ZAMPRONI, K.; BIONDI, D. Percepção dos moradores sobre a arborização de ruas da região central de Mandirituba/PR. Revista da Sociedade Brasileira de Arborização Urbana, Piracicaba, v. 10, n. 3, p. 14-23, 2015.

IBGE - Instituto Brasileiro de Geografia e Estatística. Censo 2017. Disponível em: http://www.ibge.gov.br/. Acesso em: 03 mai. 2018.

IBGE - Instituto Brasileiro de Geografia e Estatística. IBGE Cidades. Disponível em: https://cidades.ibge.gov.br/brasil/sp/arealva/panorama. Acesso em: 18 de jul. de 2019.

JORGENSEN, E. Urban Forestry in Canada. Forestry Chronicle, Toronto, v. 46, n. 6, p. $529,1970$.

LACERDA, N. P.; SOUTO, P. C.; DIAS, R. S.; SOUTO, L.; SOUTO, J. Percepção dos residentes sobre a arborização da cidade de São José de Piranhas-PB. Revista da Sociedade Brasileira de Arborização Urbana, Piracicaba, v. 5, n. 4, p. 81-95, 2010. 
LOURENÇO, J. S. G. Percepção da população sobre a arborização da cidade de São João Del-Rei, Minas Gerais. Revista da Sociedade Brasileira de Arborização Urbana, Piracicaba, v. 12, n. 2, p. 62-72, 2017.

MILANO, M.S. A cidade, os espaços abertos e a vegetação. In: CONGRESSO BRASILEIRO SOBRE ARBORIZAÇÃO URBANA, 1., 1992, Vitória. Anais [...]Vitória: Sociedade Brasileira Arborização Urbana. 1992. v. 1, p. 3-14

MILLER, R. W. Urban forestry: Planning and managing urban greenspaces (2nd ed.). Upper Saddle River, NJ: Prentice Hall, 1997, 512 p.

MONTEIRO, M. M. G.; TETTO, A. F.; BIONDI, D.; SILVA, R. R. S. Percepção dos usuários em relação à arborização da Avenida Cândido de Abreu - Curitiba - PR. Revista da

Sociedade Brasileira de Arborização Urbana, Piracicaba, v. 8, n. 2, p. 20-34, 2013.

OLIVEIRA, G. S.; TAVARES, A. A. Levantamento e caracterização das variáveis utilizadas em estudos sobre arborização urbana. Revista da Sociedade Brasileira de Arborização Urbana, Piracicaba, v. 7, n. 3, p. 75-87, 2012.

OLIVEIRA, V. P.; DIAS, J. G. S.; RIBEIRO, A. T.; OLIVEIRA, L. B. S.; MARIANO, M. O.; PINTO, D. S. A percepção da população sobre arborização em um conjunto habitacional no município de Paragominas - PA. Revista da Sociedade Brasileira de Arborização Urbana, Piracicaba, v. 12, n. 3, p. 27-36, 2017.

RODRIGUES, T. D.; MALAFAIA, G.; QUEIROZ, S. E. E.; RODRIGUES, A. S. L. Percepção sobre arborização de moradores em três áreas de Pires do Rio - Goiás. Revista de estudos ambientais, Blumenau, v. 12, n. 2, p. 47-61, 2010.

ROLON, M. S.; SIQUEIRA, M. V. B. M. Diagnóstico arbóreo comparativo em bairros de Lençóis Paulista - SP. Revista da Sociedade Brasileira de Arborização Urbana, Piracicaba, v. 13, n. 1, p. 43-56, 2018.

ROPPA, C.; FALKENBERG, J. R.; STANGERLIN, D. M.; BRUN, F. G. K.; BRUN, E. J.; LONGHI, S. J. Diagnóstico da percepção dos moradores sobre a arborização urbana na vila Estação Colônia - Bairro Camobi, Santa Maria - RS. Revista da Sociedade Brasileira de Arborização Urbana, Piracicaba, v. 2, n. 2, p.11-30, 2007.

SANTOS, M. O., MAIA, L. P. S. S., OLIVEIRA, E. D., SILVA NETO, J. C. A., CELLA, W. Percepção ambiental sobre a arborização urbana no 4587111172. Revista Ra'e Ga: o espaço geográfico em análise, Curitiba, v. 44, p. 231 - 241, 2018.

SHAMS, J. C. A.; GIACOMELI, D. C.; SUCOMINE, N. M. Emprego da arborização na melhoria do conforto térmico nos espaços livres públicos. Revista da Sociedade Brasileira de Arborização Urbana, Piracicaba, v. 4, n. 4, p. 1-16, 2009.

SOUZA, S. M.; CARDOSO, A. L., SILVA, A. G. Estudo da percepção sobre arborização urbana, no município de Alegre - ES. Revista da Sociedade Brasileira de Arborização Urbana, Piracicaba, v. 8, n. 2, p. 68-85, 2013.

SUFIA, M. C. S.; SOUZA, G. S.; SIQUEIRA, M. V. B. M. Percepção ambiental sobre arborização urbana em regiões distintas do município de Bauru - SP. Revista da Sociedade Brasileira de Arborização Urbana, Curitiba, v.13, n. 4, p. 15-28, 2019. 